\title{
On comparison of recycled LDPE and LDPE-bakelite composite based 3D printed patch antenna
}

\author{
*Rupinder Singh ${ }^{1}$, Sanjeev Kumar ${ }^{2}$, Amrinder Pal Singh ${ }^{2}$, Yang $\mathrm{Wei}^{3}$ \\ ${ }^{1}$ Department of Mechanical Engineering, National Institute of Technical Teachers Training and Research, \\ Chandigarh \\ ${ }^{2}$ Department of Mechanical Engineering, University Institute of Engineering and Technology, Panjab University \\ Chandigarh \\ ${ }^{3}$ Department of Engineering, Nottingham Trent University, U.K \\ *Corresponding Author Email: rupindersingh@ nitttrchd.ac.in
}

\begin{abstract}
In past two decades number of studies has been reported on use of thermoplastics as substrate for 3D printed patch antennas. However, no work has been reported on thermoplasticthermosetting composite based substrate for 3D printed patch antennas and their mechanical, morphological, rheological and radiofrequency (RF) characterization for sensing applications. In this study low-density polyethylene (LDPE) and LDPE-5\% bakelite (BAK) composite based patch antenna (resonating frequency $2.45 \mathrm{GHz}$ ) were printed (for secondary recycling) on fused deposition modelling (FDM) setup. The RF characteristics were measured using vector network analyzer (VNA). Ring resonator test was used for measuring the dielectric properties of substrates (which suggests that the di-electric constant $\left(\varepsilon_{r}\right)$ and loss tangent $(\tan \delta)$ for LDPE was 2.282 and 0.0045 , where as for LDPE-5\%BAK the calculated $\varepsilon_{r}$ and $\tan \delta$ was $2.0663,0.0051$ respectively). This study highlights that for LDPE-5\%BAK composite there was marginal increase in size of patch antenna; but this resulted into improved transmittance, gain, and return loss for typical sensor applications. As regards to printability of substrate, $5 \%$ BAK resulted into melt flow index (MFI) of $9.96 \mathrm{~g} / 10 \mathrm{~min}$ in contrast to $12.208 \mathrm{~g} / 10 \mathrm{~min}$ for neat LDPE sample. The selected LDPE-5\%BAK composite resulted in peak strength (PS) and break strength (BS) of $16.08 \mathrm{MPa}$ and $14.47 \mathrm{MPa}\left(\right.$ at $180^{\circ} \mathrm{C}$ screw temperature, 110 $\mathrm{rpm}$ and $11 \mathrm{~kg}$ load) while processing with twin screw extruder (TSE), which was observed better than the neat LDPE (PS 11.98 MPa, BS 10.79MPa). The results were supported with porosity (\%), surface roughness (Ra) analysis based upon scanning electron microscopy (SEM) and bond strength using attenuated total reflection (ATR) based Fourier transformed infrared (FTIR) analysis.
\end{abstract}

Keywords: LDPE; bakelite; antenna; recycling; fused deposition modelling; vector network analysis

Introduction: The waste in the form of plastic has been increasing day by day and prediction has been made that it will be in abundance in near future [1]. The disposal of solid plastic waste through burning will cause more pollution due to release of toxic gases [2]. Commercially the thermoplastics are being recycled but recycling of thermosetting has many challenges (such as technological and cost effective issues). The BAK is one of the most commonly used thermosetting plastics contributing to large amount of plastic waste. The BAK has properties like: high hardness, strength and rigidity due to its three dimensional cross linked network structure and thermal stability. Therefore, its utility as a polymer cannot be ignored but recycling of BAK by the conventional processing techniques is still a challenge [3]. One of the most commonly used thermoplastics, as food packaging materials, sheets and films, is LPDE. It has a good flexibility, transparency, fluidity and glossy look [4] along with better crystallinity and ability to retain toughness and adaptability over a wide temperature [5] thus making it one of the most important thermoplastic.

In past two decades, different thermoplastic polymers have shown a great application as substrates for patch antennas due to light weight, low cost, robust design [6]. An antenna as a transmitter or receiver prepared through recycling of thermoplastic (may be primary or secondary) has numerous applications resulting into better way of solid plastic waste management [7]. Antenna is a fundamental communication instrument used for transmitting signals wirelessly in numerous engineering applications. It can send or receive data from one system to another by propagating signals through the air space within a specific range [8]. The antenna providing desired performance having compact size with ease of fabrication at low cost is preferred which may be suitable prepared with thermoplastic based substrates [7]. It has been reported that micro-strip patch antennas (MPA) are the most suitable antenna structures because of its compactness, light weight simple profile and planar design that can be fabricated easily with FDM [9]. A MPA is made up of a dielectric substrate having 
a radiating-patch or active patch printed on the top-side and a ground-part is printed on the bottom of the substrate [10]. The radiating patch and ground part are made up of good conducting materials such as $\mathrm{Cu}, \mathrm{Al}$ or $\mathrm{Au}$. There are lot of shapes, like square, circular, rectangular, elliptical or triangular, for designing patches in different applications. Circular and rectangular patches are mostly preferred due to ease of fabrication and design [7]. It has been reported that surface waves propagate through the substrate that also provides the mechanical strength to the overall antenna structure. Change in substrate material and thickness causes changes in the system performance [11]. The $\varepsilon_{\mathrm{r}}$ of substrate is important factor in determining the physical parameters of antennas, and the characteristic impedance of circuitry, feed line width, and passive components as microwave filter, whereas the loss in dielectric medium is determined by tan $\delta$ of substrate [12]. Usually thick substrates are desirable for good antenna performance whose $\varepsilon_{\mathrm{r}}$ is in the lower end of the range because they provide better efficiency, larger bandwidth, loosely bound fields for radiation into space, but at the expense of larger element size. Thin substrates with higher dielectric constants are desirable for microwave circuitry because they require tightly bound fields to minimize undesired radiation and coupling, and lead to smaller element sizes; however, because of their greater losses, they are less efficient and have relatively smaller bandwidths. A number of substrates are available for designing and fabricating MPA such as: Duroid® 5880, FR4, HK 04J, Polyguide, RF- 60A [13]. High dielectric substrate reduces the dimensions of the antenna since the dimensions are inversely proportions to the $\varepsilon_{\mathrm{r}}$. Voltage can be supplied to the patch using the feed line. The most used feeding techniques are coaxial probe feed, microstrip line, aperture coupling and proximity coupling [14]. MPA has shown great applications in mobile and satellite communication application [15] [16], Global Positioning System (GPS) [17] [18], Radio Frequency Identification (RFID) [19] [20], Radar Application [21] [22], Rectenna Application [23], Telemedicine Application [24], Medicinal applications [25].

In the past two decades industries and researchers has shown an increasing interest in FDM. Easy fabrication of the complicated parts at very less time and low cost has made it more popular. FDM has been studied well for design and fabrication of the mechanical structures [26]. FDM techniques are used for printing materials such as polymers, metals, ceramics, concrete or even biological tissues[27]. As demand of compact and flexible antennas has increased, FDM of polymers has shown a great application in printing substrates for antenna design of compact size with good flexibility. FDM has shown its application in microwave components including waveguides, horn antennas and directional couplers [26]. The FDM has been established as one of the most important FDM technique offering a wide range of variability in design [28]. Some parameters such as bed temperature, nozzle temperature, orientation, printing speed and infill density defines the changes in properties of material used printed using FDM [29] [30]. Design parameters and performance issues of patch antenna have been discussed in previous studies [7]. Comparison of performance parameters has been done by changing the material of the substrate like Epoxy_kevlar_xy with dielectric constant 3.6 and FR4_epoxy with dielectric constant 4.4. Wideband patch antenna has been designed by using a patch of $20 \times 12 \mathrm{~mm}^{2}$. The maximum value of return loss has been $-31.264 \mathrm{~dB}$ at $7.58 \mathrm{GHz}$ for FR4_epoxy and $-22.24 \mathrm{~dB}$ at $8.01 \mathrm{GHz}$ for epoxy_kevlar_xy. It also has been concluded that when $\varepsilon_{\mathrm{r}}$ reduces from 4.4 to 3.6 the bandwidth increases. The efficiency of the antenna also improves with low $\varepsilon_{\mathrm{r}}$ [11]. In another study authors have compared the RF and microwave performance of thermoplastic (poly methyl methacrylate (PMMA), poly lactic acid (PLA)) substrate based patch antennas with FR4 substrate patch antenna [31]. The return loss ( $S_{11}$ parametrs) has been measured as $32 \mathrm{~dB}, 18.98 \mathrm{~dB}$ and $16.36 \mathrm{~dB}$ for FR4, PMMA and PLA respectively. It has been reported that acrylonitrile butadiene styrene (ABS) is suitable for designing conformal antenna in 3D for further researcher [32]. The $\varepsilon_{\mathrm{r}}$ and $\tan \delta$ of ABS at $2.44 \mathrm{GHz}$ has been calculated as 2.74 and 0.0051 respectively. The return loss has been simulated by computer simulation technology (CST) and the results were measured by using VNA. This study highlighted that the return loss results for simulation and measurement are in close confirmation with each other. The FDM has been used to print the ABS substrate for fabricating and characterising a microwave patch antenna at a resonance frequency of $7.5 \mathrm{GHz}$ [27]. In a separate study, it has been observed that $\varepsilon_{\mathrm{r}}$ of LDPE (size $60 \times 60 \mathrm{~mm}$ with $2 \pm 0.2 \mathrm{~mm}$ thickness) has not shown any monotonic variation by thermal ageing of the substrate at a temperature of $90^{\circ} \mathrm{C}$ for 2500 hours [33]. The $\mathrm{LDPE} / \mathrm{TiO}_{2}$ and polystyrene $(\mathrm{PS}) / \mathrm{TiO}_{2}$ composite has been used as alternative substrates for MPA for portable devices [6]. 
Some studies highlighted that up to $10 \%$ BAK can be reinforced in the ABS matrix based upon MFI value. The composite has shown better tensile properties. The feedstock filament was processed on TSE at temperature $230^{\circ} \mathrm{C}, 300 \mathrm{rpm}$ and $5 \mathrm{~kg}$ load [3]. 3D printing of ABS-BAK composite has been successfully performed on FDM by varying infill ratio $(60 \%, 80 \%$ and $100 \%)$ and printing speed (50 $\mathrm{mm} / \mathrm{s}, 60 \mathrm{~mm} / \mathrm{s}$ and $70 \mathrm{~mm} / \mathrm{s}$ ) [34]. Researchers have reported use of LDPE for outdoor structures such as window frames, automobiles, pipes cables etc. [35]. The study highlights that LDPE reinforced with jute fabric (JF) resulted into reduced photo degradation and improvement in mechanical properties by using an amine light stabilizer (Chimassorb 944), a light absorbent (Tinuvin 326), and an antioxidant (Irganox 1010) with composite. This was performed to save the material from UV rays and its effects on colour degradation and poor mechanical properties. The researches have shown that thermosetting plastics can be 3D printed by reinforcing it in thermoplastics. As thermoplastics (such as ABS, LDPE etc.) have shown good application in 3D printed substrates of patch antennas [34].

The literature review reveals that significant studies have been reported on 3D printed patch antenna. But limited studies have been reported on thermoplastic patch antenna and no work has been reported on thermoplastic-thermosetting composite based 3D printed substrate for patch antennas and their mechanical, morphological, rheological and radiofrequency (RF) characterization for sensing applications. Further the use of thermoplastic and thermosetting based substrates in patch antenna may be treated as novel way of secondary recycling resulting into development of high end value added product. So, in this study LDPE and LDPE-5\% BAK composite based substrate were printed (for secondary recycling) on FDM for preparation of patch antenna (resonating frequency $2.45 \mathrm{GHz}$ ).

Materials and methods: The methodology adopted for present study is shown in Fig. 1. In this study, recycled LDPE with MFI $12.208 \mathrm{~g} /(10 \mathrm{~min})$ according to the ASTM D 1238 was selected as the matrix material. For reinforcement, recycled BAK up to $10 \mathrm{wt} \%$ has been explored for composite preparation (Table 1). It has been noticed that 7.5\% BAK in LDPE resulted into brittle feedstock filament with poor spoolable features, therefore 5\%BAK proportion in LDPE has been selected for further analysis. Based upon MFI observations (Table 1), pilot experimentation the parameters and their levels were selected for screw extrusion on TSE (Table 2). Further based upon Table 2, Table 3 shows design of experiment (DOE) as per Taguchi L9 orthogonal array (OA).

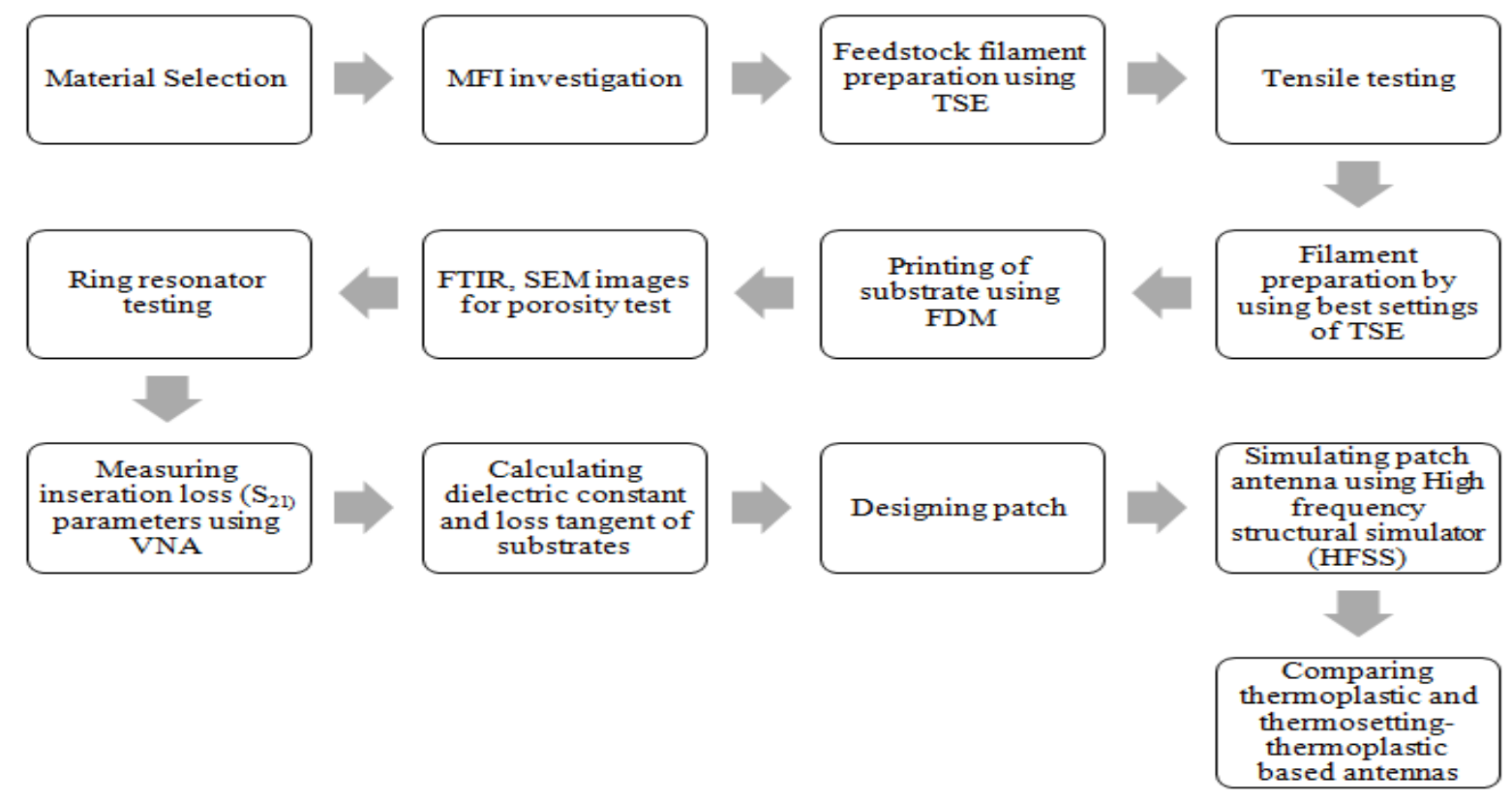

Fig. 1: Methodology adopted for present study 
Table 1: MFI observations

\begin{tabular}{|c|c|c|c|}
\hline S. No. & LDPE (Wt.\%) & BAK (Wt.\%) & MFI in g/(10min) \\
\hline 1 & $100 \%$ & $0 \%$ & 12.208 \\
\hline 2 & $97.5 \%$ & $2.5 \%$ & 11.59 \\
\hline 3 & $95 \%$ & $5 \%$ & 9.96 \\
\hline 4 & $92.5 \%$ & $7.5 \%$ & 9.65 \\
\hline 5 & $90 \%$ & $10 \%$ & Material stuck in barrel \\
\hline
\end{tabular}

Table 2: Input parameters and their levels

\begin{tabular}{|c|c|cc|c|}
\hline Parameter Levels & Screw temperature $\left({ }^{\circ} \mathrm{C}\right)$ & Rotation per minute & $(\mathrm{rpm})$ & $\mathrm{Load}(\mathrm{kg})$ \\
\hline 1 & 180 & 90 & 5 \\
\hline 2 & 185 & 100 & 8 \\
\hline 3 & 190 & 110 & 11 \\
\hline
\end{tabular}

Table 3: DOE based upon L9 OA for TSE

\begin{tabular}{|c|c|c|c|}
\hline Expt. No. & Screw Temperature $\left({ }^{\circ} \mathrm{C}\right)$ & Rotation per minute $\quad(\mathrm{rpm})$ & Load $(\mathrm{kg})$ \\
\hline $\mathrm{C} 1$ & 180 & 90 & 5 \\
\hline $\mathrm{C} 2$ & 180 & 100 & 8 \\
\hline C3 & 180 & 110 & 11 \\
\hline $\mathrm{C} 4$ & 185 & 90 & 8 \\
\hline $\mathrm{C5}$ & 185 & 100 & 11 \\
\hline C6 & 185 & 110 & 5 \\
\hline C7 & 190 & 90 & 11 \\
\hline C8 & 190 & 100 & 5 \\
\hline C9 & 190 & 110 & 8 \\
\hline
\end{tabular}

The wire samples extruded as per Table 3 has been tested on universal testing machine (UTM) Make: Shanta Engineering, Pune, India. Fig. 2 shows the extrusion of filament (diameter $=2.85 \mathrm{~mm}$ ) using TSE. The mechanical properties such as peak elongation (PE), break elongation (BE), break strength (BS), peak strength (PS) has been tested (Fig. 3). Based on these properties wire sample with highest strength has been selected and at that extrusion setting the feedstock filament of required length has been prepared for 3D printing of samples using FDM (Table 4). Fig. 4 shows the results of mechanical properties on stress strain curve (as per Table 4).

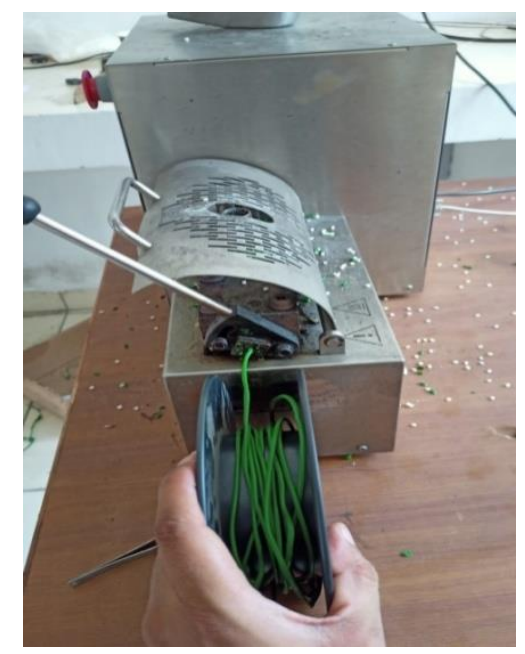

(a)

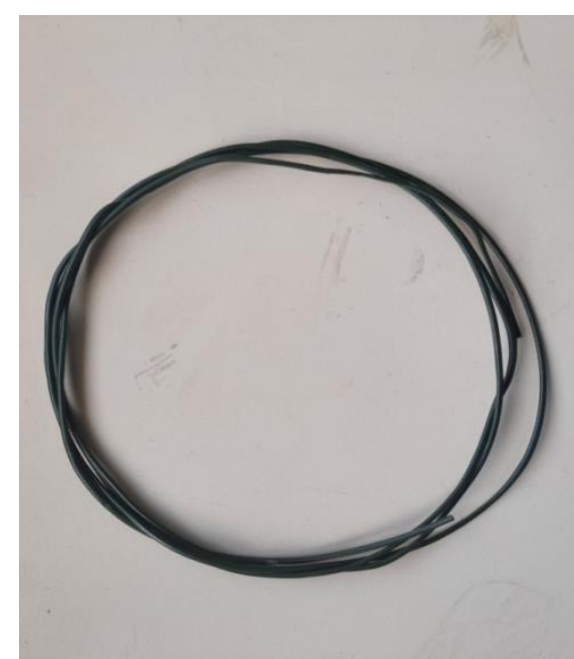

(b)

Fig. 2: Extrusion of LDPE filament (a), extruded filament of LDPE-BAK composite (b) 


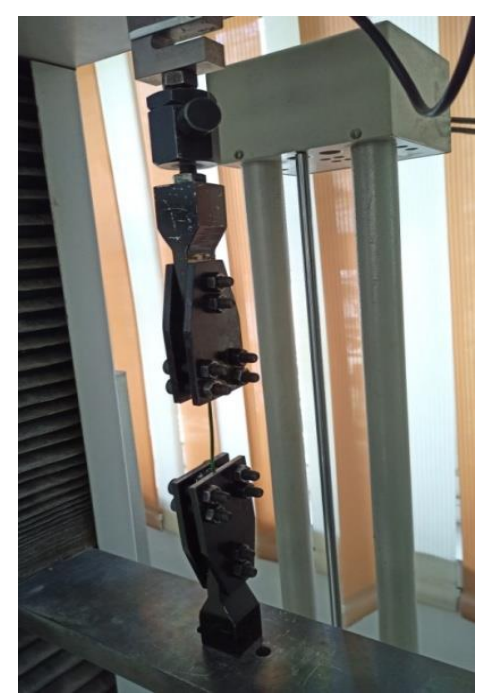

(a)

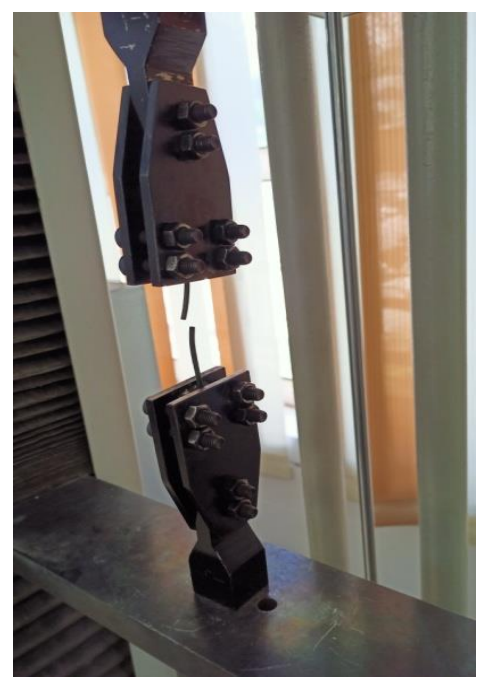

(b)

Fig. 3: Tensile testing on UTM before breaking (a) and after breaking (b)

Table 4: Observed mechanical properties as per Table 3

\begin{tabular}{|c|c|c|c|c|c|c|}
\hline Sample & PE $(\mathrm{mm})$ & PS $(\mathrm{MPa})$ & $\mathrm{BE}(\mathrm{mm})$ & $\mathrm{BS}(\mathrm{MPa})$ & $\begin{array}{c}\text { Young's } \\
\text { Modulus } \\
(\mathrm{MPa})\end{array}$ & $\begin{array}{c}\text { Modulus of } \\
\text { toughness } \\
(\mathrm{MPa})\end{array}$ \\
\hline LDPE & $5.46 \pm 0.5$ & $11.9 \pm 0.8$ & $7.14 \pm 0.49$ & $10.7 \pm 0.9$ & $108 \pm 2.5$ & $0.75 \pm 0.05$ \\
\hline C1 & $3.99 \pm 0.45$ & $11.1 \pm 0.9$ & $6.93 \pm 0.41$ & $10.0 \pm 0.7$ & $139 \pm 2.9$ & $0.70 \pm 0.04$ \\
\hline C2 & $3.36 \pm 0.43$ & $9.3 \pm 0.8$ & $4.2 \pm 0.41$ & $8.4 \pm 0.4$ & $134 \pm 1.9$ & $0.33 \pm 0.05$ \\
\hline C3 & $4.83 \pm 0.51$ & $16.0 \pm 0.8$ & $4.83 \pm 0.49$ & $14.4 \pm 0.7$ & $160 \pm 3.9$ & $0.72 \pm 0.08$ \\
\hline C4 & $6.72 \pm 0.52$ & $9.0 \pm 0.9$ & $7.77 \pm 0.51$ & $8.0 \pm 0.9$ & $69 \pm 2.1$ & $0.64 \pm 0.07$ \\
\hline C5 & $6.93 \pm 0.50$ & $15.3 \pm 0.9$ & $7.14 \pm 0.45$ & $13.8 \pm 0.5$ & $109 \pm 1.9$ & $0.96 \pm 0.05$ \\
\hline C6 & $5.25 \pm 0.43$ & $13.2 \pm 0.9$ & $5.46 \pm 0.41$ & $11.9 \pm 0.6$ & $120 \pm 1.8$ & $0.65 \pm 0.08$ \\
\hline C7 & $2.94 \pm 0.50$ & $12.2 \pm 0.9$ & $3.15 \pm 0.49$ & $11.0 \pm 0.6$ & $204 \pm 3.2$ & $0.33 \pm 0.05$ \\
\hline C8 & $3.78 \pm 0.43$ & $13.6 \pm 0.8$ & $3.99 \pm 0.42$ & $12.3 \pm 0.1$ & $171 \pm 1.8$ & $0.49 \pm 0.04$ \\
\hline C9 & $4.41 \pm 0.32$ & $11.2 \pm 0.9$ & $4.41 \pm 0.47$ & $10.1 \pm 0.6$ & $125 \pm 1.1$ & $0.45 \pm 0.03$ \\
\hline
\end{tabular}

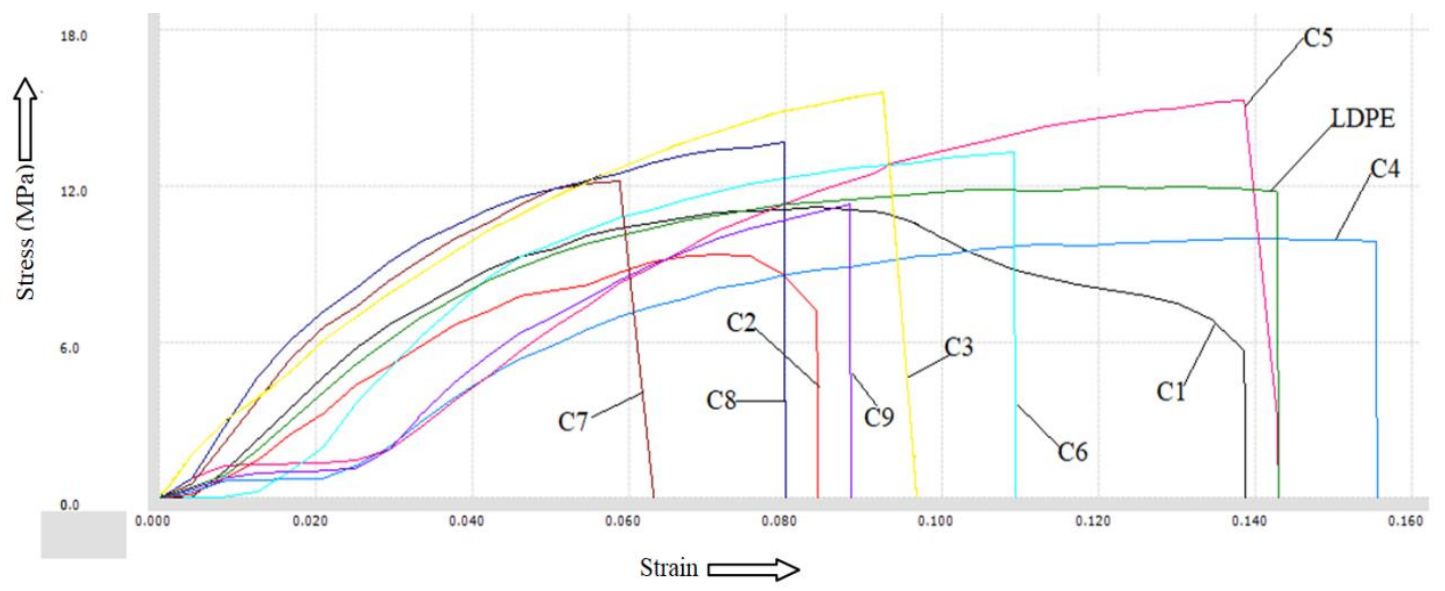

Fig. 4: UTM results on Stress strain curve as per Table 4

The substrates of LDPE and LDPE-BAK were printed on open source FDM (Make: ultimaker ${ }^{2+}$ ) shown in Fig. 5. The substrate of size $50 \times 40 \times 0.75 \mathrm{~mm}$ has been designed in solid works and converted into .STL format and then printing has been performed by using ultimaker ${ }^{2+}$ commercial $^{2}$ 
printer at $45^{\circ}$ raster angle, $100 \%$ infill density, infill pattern rectilinear, 03 number of perimeter, 02 top and bottom layers, nozzle temperature $230^{\circ} \mathrm{C}$ and bed temperature $60^{\circ} \mathrm{C}$.

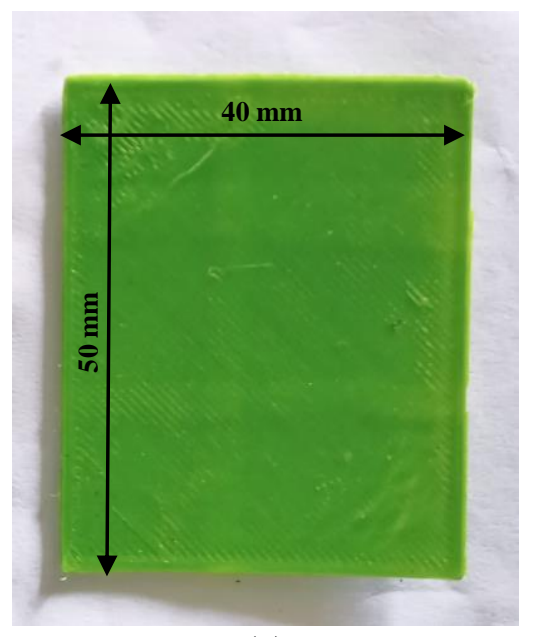

(a)

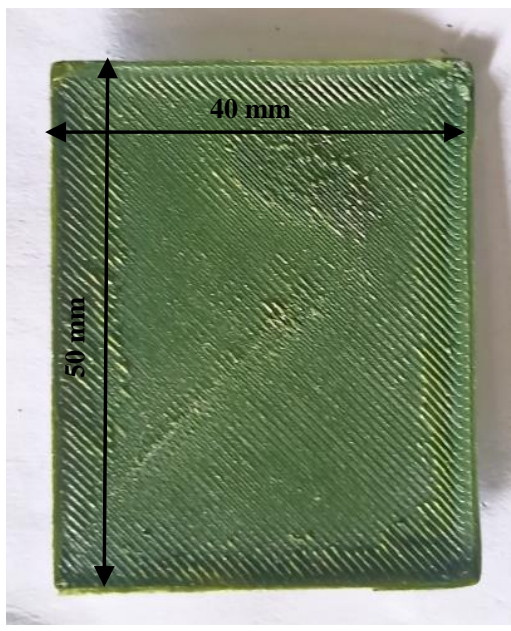

(b)

Fig. 5: 3D printed LDPE substrate (a) and 3D printed LDPE-5\%BAK substrate (b)

\section{Results and Discussion}

As observed from Table 4, sample C2 has least strength (even lower than LDPE sample) and sample $\mathrm{C} 3$ has shown highest strength so for further analysis signal to noise (SN) ratio was calculated for PS with maximum the better type case (Table 5) and corresponding main effect plot is shown in Fig.6. For maximum the better type case, $\mathrm{SN}$ ratio can be calculated as:

$$
\eta=-10 \log \left[\frac{1}{n} \sum_{k=1}^{n} \frac{1}{y^{2}}\right]
$$

Where $\eta$ is $\mathrm{SN}$ ratio, $\mathrm{n}$ is the no. of the experiment, and $y$ is the material properties at experiment no. $\mathrm{k}$.

Based upon Table 5, analysis of variance (ANOVA) was performed (Table 6).

Table 5: Calculated SN for PS

\begin{tabular}{|c|c|}
\hline Sample No. & SN for PS (dB) \\
\hline C1 & 20.9766 \\
\hline C2 & 19.4441 \\
\hline C3 & 24.1257 \\
\hline C4 & 19.1713 \\
\hline C5 & 23.7448 \\
\hline C6 & 22.4705 \\
\hline C7 & 21.7910 \\
\hline C8 & 22.7217 \\
\hline C9 & 21.0539 \\
\hline
\end{tabular}

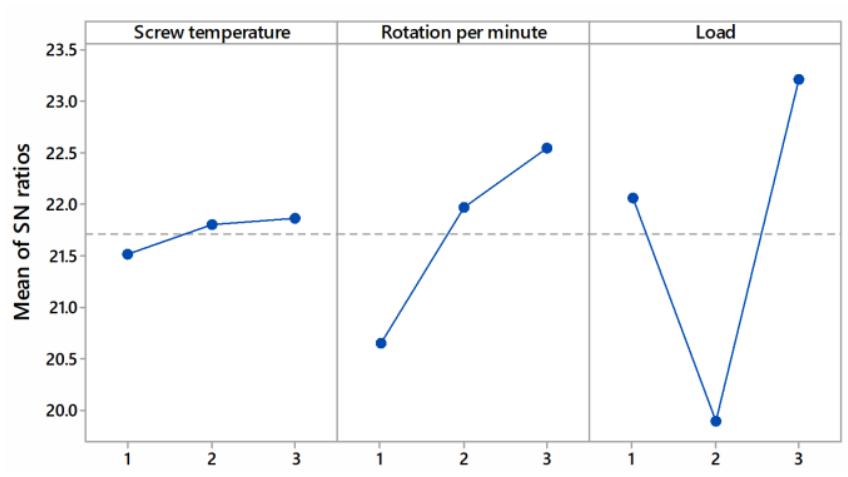

Fig. 6: Main effect plot for PS SN ratio

Table 6: ANOVA for SN ratios

\begin{tabular}{|c|c|c|c|c|c|}
\hline Source & DF & Seq. SS & F & P & $\%$ C \\
\hline Screw temperature & 2 & 0.1977 & 0.18 & 0.845 & 0.819 \\
\hline Rotation per minute & 2 & 5.7131 & 5.30 & 0.159 & 23.67 \\
\hline Load & 2 & 17.1434 & 15.92 & 0.059 & 71.04 \\
\hline Residual Error & 2 & 1.0770 & & & 4.46 \\
\hline Total & 8 & 24.1312 & & & \\
\hline
\end{tabular}

Note: DF: Degree of freedom, Seq. SS: Sequential sum of squares, F: Fisher's value, P: Probability, $\%$ : Percentage contribution 
As observed from Fig. 6, the best settings for PS are: screw temperature $190^{\circ} \mathrm{C}, 110 \mathrm{rpm}$ and $11 \mathrm{~kg}$ load. Further to ascertain the $\% \mathrm{C}$ of input parameters it has been observed that at $95 \%$ confidence level only load is significant (that too marginally for $\mathrm{P}$ value $\leq 0.05$ ). The other parameters were observed as insignificant (Table 6). Overall high screw temperature, rpm and load may have led to better/ uniform distribution of BAK in LDPE resulting into more PS. In order to further ascertain this behaviour attenuated total reflection (ATR) based FTIR analysis of LDPE and LDPE-5\%BAK composite was performed by incedence of IR rays ranging from $500-4000 \mathrm{~cm}^{-1}$ wavenumber (WN) on surface of 3D printed subtrates. The changes occurred in the absorbance of substrate and bonding characteristics of LDPE with and without reinforcement were investigated for characterization of the base and composite polymer matrix for sensor applications. Fig. 7 shows the ATR-FTIR absorbance spectrum of LDPE (a) and LDPE-5\%BAK composite.

It was observed that the functional groups present in the LDPE substrates shows significant changes in absorbance spectra due to the presence of BAK. In case of LDPE sample (Fig. 7(a)), $-\mathrm{CH}_{2}$ - group shows the strong peak intensity of absorbance 4 for IR intensity range $3600-3800 \mathrm{~cm}^{-1} \mathrm{WN}$. After reinforcement of BAK, symmetrical strtching was observed (Fig. 7(b)) in the functional group for the same IR range. At $2350 \mathrm{~cm}^{-1} \mathrm{WN}$ weak intensity amorphous phase of LDPE was observed which was reduced after addition of BAK in composite matrix (as no significant peak highlighting this phase was obsered). The presence of - $\mathrm{CH}$ - bond was observed in LDPE for 1400-1600WN whereas spread observed in composite for same range indicated the change in bond angle of - $\mathrm{CH}$ - due to bending of molecules. The absorbance peaks at $1055-1251 \mathrm{~cm}^{-1} \mathrm{WN}$ in (Fig. 7(a)) of LDPE highlights the weak absorption of IR by $-\mathrm{CH}_{3}$ - functional group. On the other hand the same group has shown frequent movement (known as wagging) in composite sample for the same IR range intensity. This analysis signifies that reinforcement of BAK in LDPE strongly affects the bond strength and movement of functional groups in the base LDPE matrix due to which the composition LDPE-5\%BAK may be used for 3D printed sensor fabrication with improved bonding characteristics. Based upon observations in Fig. 6, two feed stock filaments (of LDPE and LDPE-5\%BAK) were prepared at $190^{\circ} \mathrm{C}, 110 \mathrm{rpm}$ and $11 \mathrm{~kg}$ load for final 3D printing of substrate. Further porosity analysis as morphological property of material has been performed on SEM images by using metallurgical image analysis software (MIAS). Fig. 8 and 9 shows SEM image and porosity analysis for wire sample C2 and C3 at cross-section and along length has been performed, which clearly justifies better PS for sample C3. Further the SEM images of 3D printed samples (LDPE and LDPE-5\%BAK) were processed for porosity analysis, Ra analysis, which clearly indicate that LDPE-5\%BAK resulted into improved surface properties, hence may be consider as better option for sensor applications (Fig. 10).

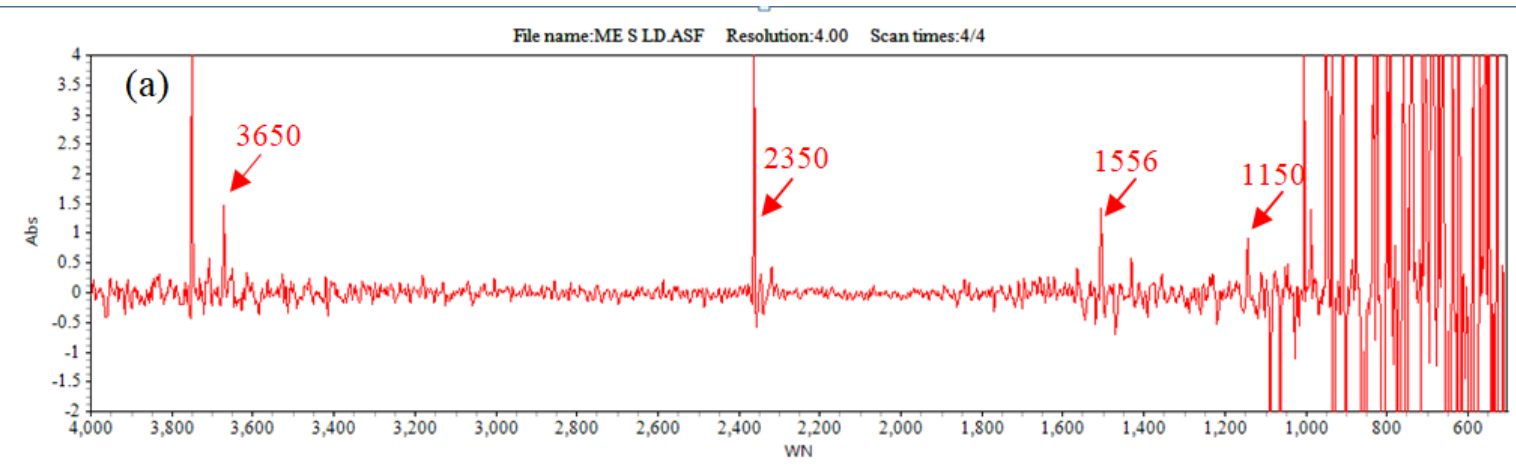

(a) 


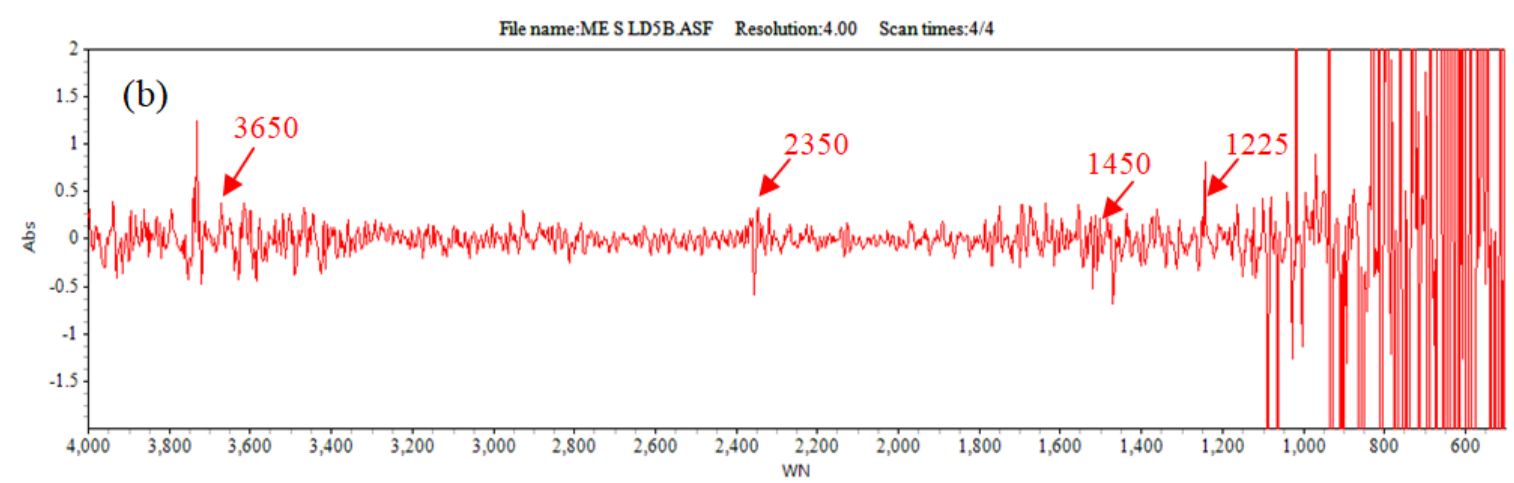

(b)

Fig. 7: ATR-FTIR spectrum for absorbance of LDPE (a) and LDPE-5\%BAK composite (b)

From the application point of view, micro strip ring resonator has been used for measuring the $\varepsilon_{r}$ and $\tan \delta$ of the substrate. It has been reported that for ease of fabrication, planar structure, compact size and high quality factor have made ring resonator popular technique for establishing RF characteristics. Radiation losses in ring resonator are very less resulting in more accuracy in measurement [36]. Ring resonator consists of a ring type conductor material and transmission lines on the substrate used for determining the $\varepsilon_{r}$ of any material. Width for feed line has been calculated for impedance $50 \mathrm{ohm}$. There is a small gap between the ring and feed lines ranging from 0.1 to 1.0 times of width of feed line [37]. Basic structure of ring resonator used in present study is shown in Fig. 11.

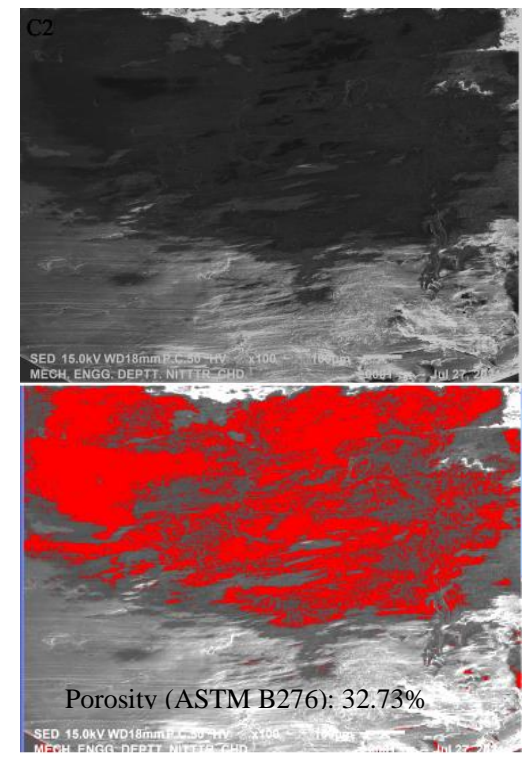

(a)

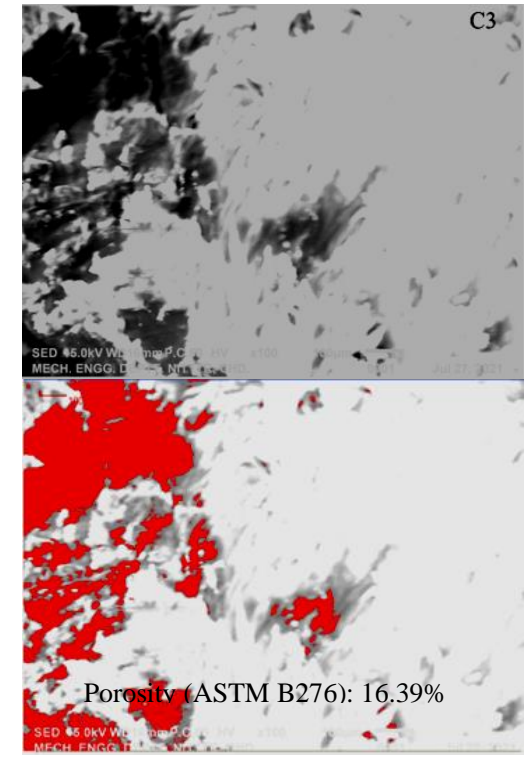

(b)

Fig. 8: SEM images (at× 100) wire sample C2 (a) and C3 at cross section (b)
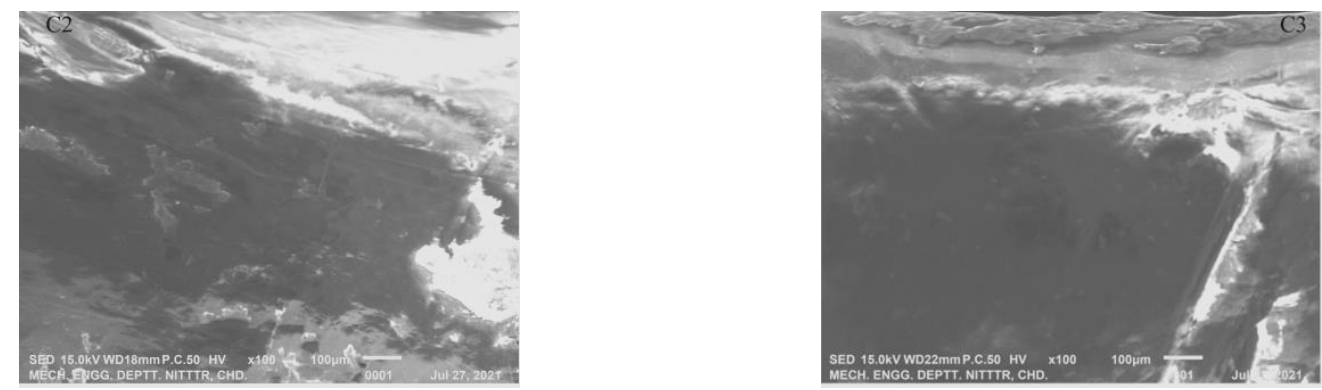


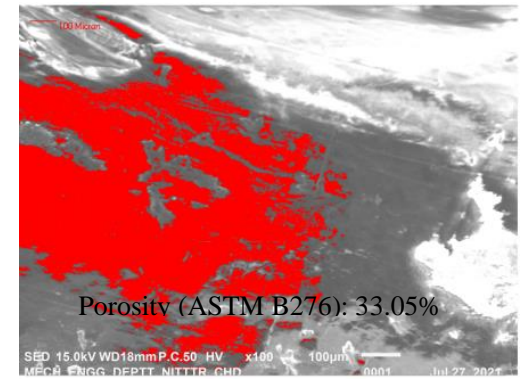

(a)

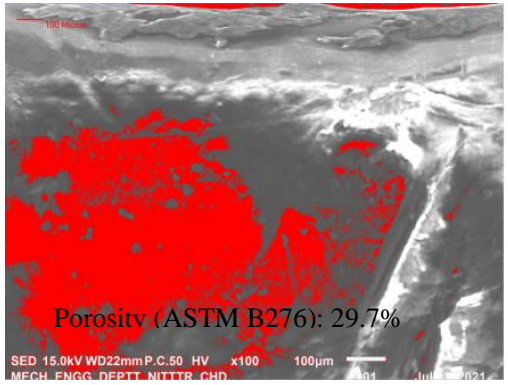

(b)

Fig. 9: SEM images (at $\times 100)$ wire sample $C 2$ (a) and $C 3$ along the length (b)
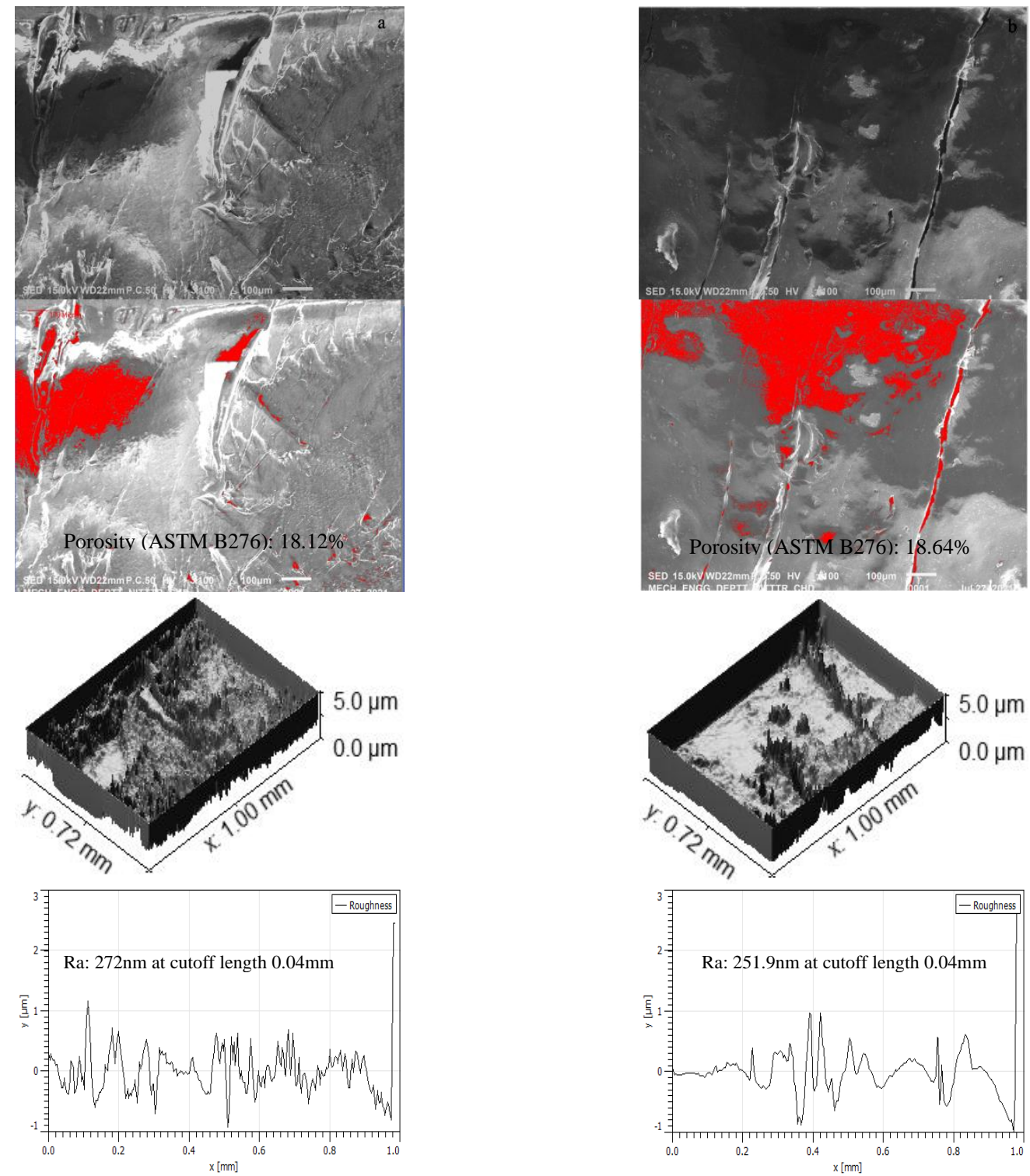

(a)

(b)

Fig. 10: SEM images (at× 100) (a) LDPE, (b) LDPE-5\%BAK 


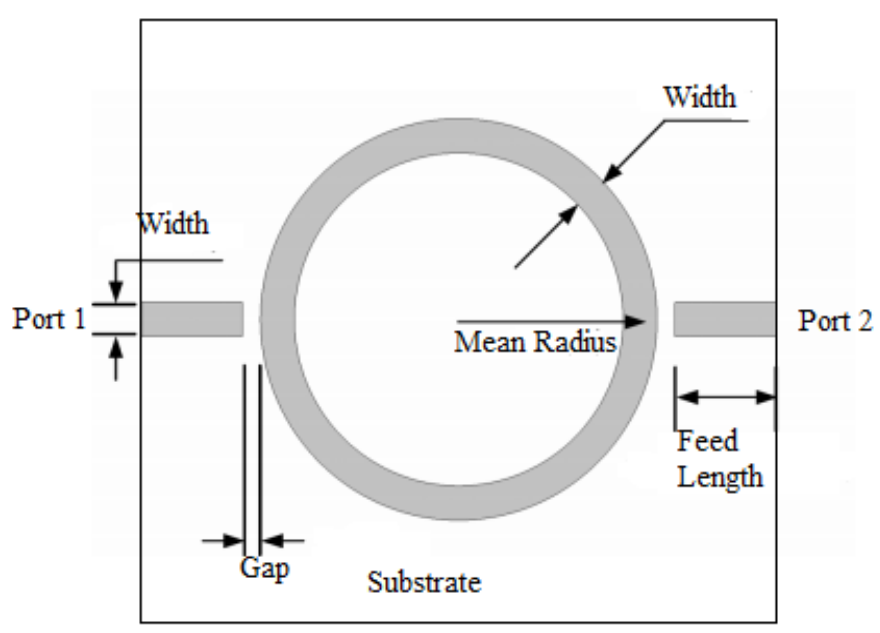

Fig. 11: Basic structure of ring resonator [26]

For analysis purpose in this work $\varepsilon_{r}=3$ has been assumed initially for both substrates (LDPE and LDPE-5\%BAK) and ring resonator has been designed for $2.45 \mathrm{GHz}$ by using equations from the previous literature [37].

$2 \pi R=n \lambda_{g}$ for $\mathrm{n}=1,2,3$

Here, $\mathrm{R}$ is the mean radius of the ring and $\mathrm{n}$ is the harmonic order of resonance.

Guided wavelength $\left(\lambda_{g}\right)$ was calculated by using following relation:

$\lambda_{g}=\frac{c}{\sqrt{\left(\varepsilon_{\text {eff }}\right)}} * \frac{1}{f}$

$\mathrm{c}$ is the velocity of light, $\mathrm{f}$ is the resonant frequency, $\lambda_{g}$ is the guided wavelength or wavelength in substrate and $\varepsilon_{e f f}$ is the effective dielectric constant and it is given by the relation of:

$\epsilon_{e f f}=\left[\frac{\epsilon_{r}+1}{2}\right]+\left[\left(\frac{\epsilon_{r}-1}{2}\right)\left(1+12 \frac{h}{w}\right)^{-0.5}\right]$

Where, $\epsilon_{r}$ is relative dielectric constant, $\mathrm{w}$ is the width of ring and $\mathrm{h}$ is the substrate thickness.

Feed line (transmission line) length was computed using following relation:

Feed line length $=\frac{\lambda_{g}}{4}$

Inner and outer radius of the ring was computed by subtraction and addition of half of width of micro strip to the mean radius respectively. It is given by,

Inner radius: $R-\frac{w}{2}$

Outer radius: $R+\frac{w}{2}$

The dimensions of ring resonator used in this work are shown in Table 7 and Fig. 12.

Table 7: Various dimensions of the ring resonator

\begin{tabular}{|c|c|}
\hline Parameters & Values \\
\hline Mean radius & $12.5 \mathrm{~mm}$ \\
\hline Width of feed line & $1.9 \mathrm{~mm}$ \\
\hline Feed line length & $10.65 \mathrm{~mm}$ \\
\hline
\end{tabular}




\begin{tabular}{|c|c|}
\hline Coupling gap & $0.9 \mathrm{~mm}$ \\
\hline Total length of substrate & $50 \mathrm{~mm}$ \\
\hline Total width of substrate & $40 \mathrm{~mm}$ \\
\hline Inner radius of ring & $13.45 \mathrm{~mm}$ \\
\hline Outer radius of ring & $11.55 \mathrm{~mm}$ \\
\hline Substrate used & LDPE and LDPE-5\%BAK \\
\hline
\end{tabular}

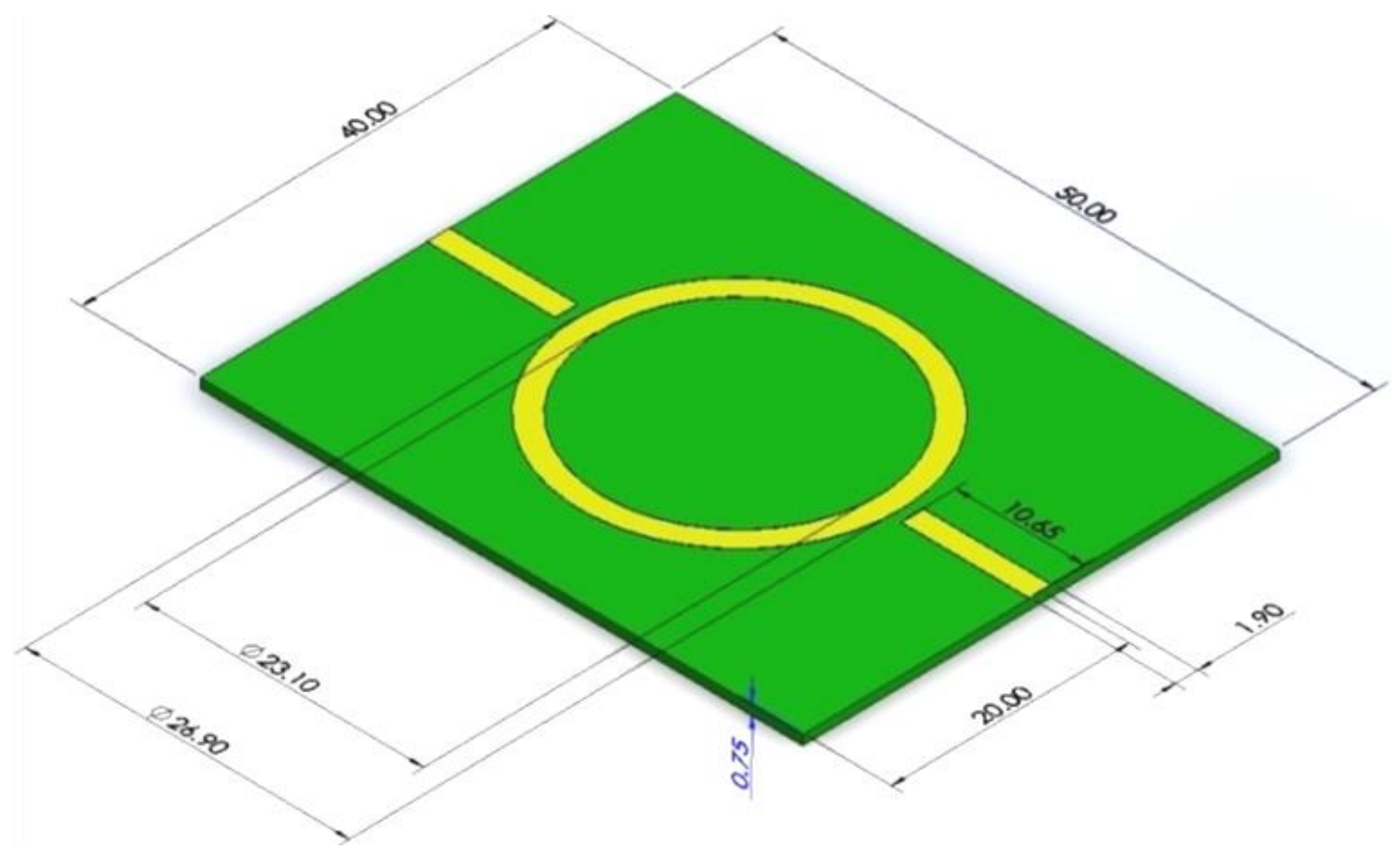

Fig. 12: CAD design of ring resonator

The $\mathrm{Cu}$ tape of thickness $0.08 \mathrm{~mm}$ has been used as conductor for ring, feed lines and ground plane and right angles connectors were used having impedance load of $50 \mathrm{ohm}$ (Fig. 13).

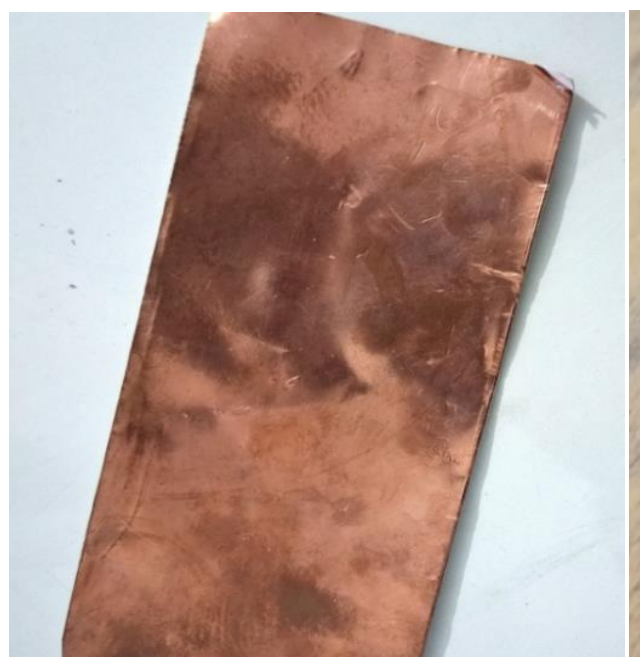

Fig. 13: (a) Cu tape

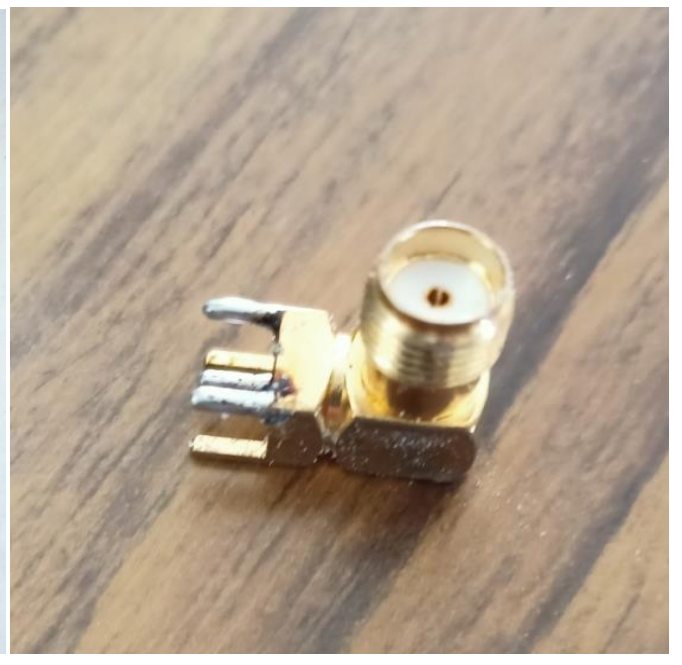

(b) Connector 
The $\mathrm{Cu}$ tape was cut in the shape of ring and feed lines and then applied on the substrate and $\mathrm{Cu}$ tape was also applied on the ground plane. After this the connectors were soldered on the feed lines (Fig. 14(a-d)).

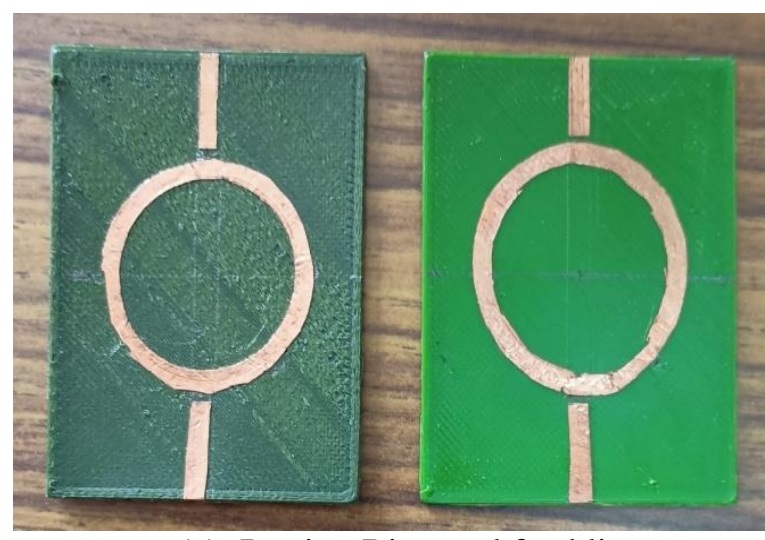

(a) Pasting Ring and feed lines

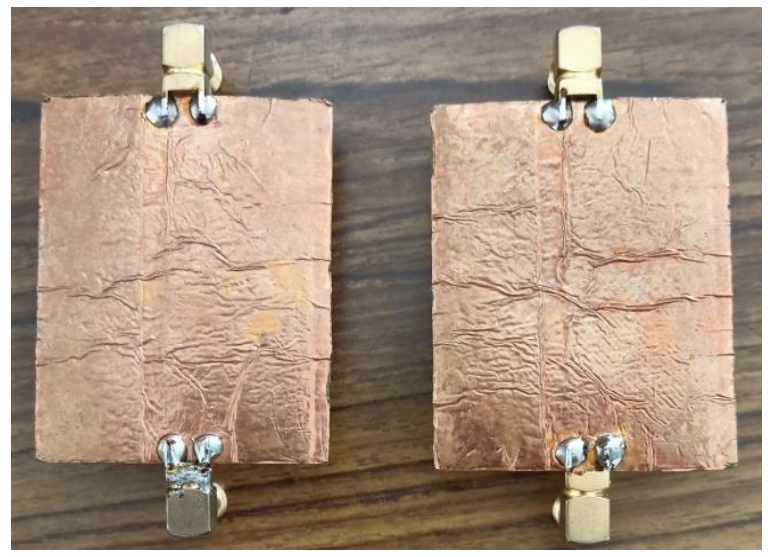

(c) Soldering connector with ground

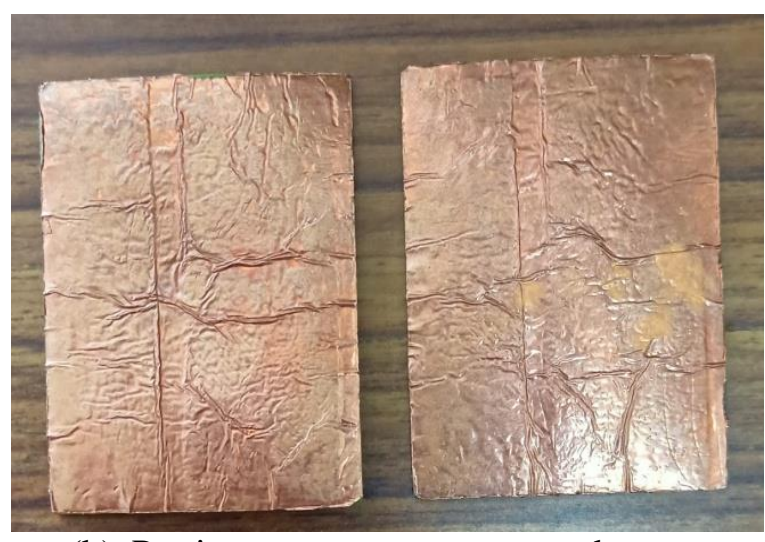

(b) Pasting copper taper as ground

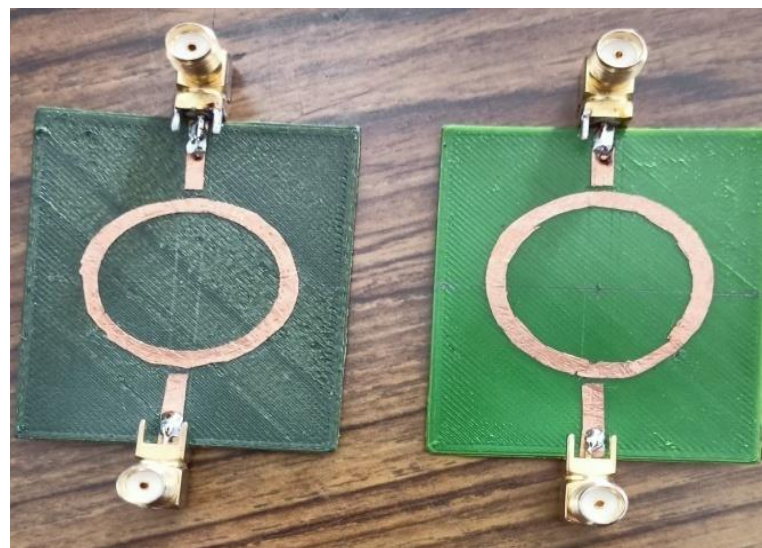

(d) Soldering Connector with Feed lines

Fig. 14: Steps for preparing ring resonator patch on both substrates

For further analysis VNA has been used. The VNA consists of a signal source, a receiver and a display. A display shows the response measured at specific frequency in the form of magnitude and phase data [38]. The $S_{21}$ parameters have been calculated using a range $9 \mathrm{KHz}$ to $6 \mathrm{GHz}$. $S_{21}$ parameters are used to find the resonating frequency antennas. Calibration of VNA at port 1 and port 2 has been done using four known standards (through, open, short, match) by using a calibration kit. Load has been kept $50 \mathrm{ohm}$ for calibration at both ports. Ports of LDPE and LDPE-5\%BAK composite based antenna have been connected to port 1 and port 2 then values were measured for a span of $4 \mathrm{GHz}$ ( $2 \mathrm{GHz}$ to $6 \mathrm{GHz}$ ). It was observed that ring resonator based on LDPE substrate was resonating at $2.755 \mathrm{GHz}$ with an insertion loss of $-35.7 \mathrm{~dB}$ and ring resonator based on LDPE$5 \%$ BAK substrate resonated at $2.874 \mathrm{GHz}$ with an insertion loss of $-42.39 \mathrm{~dB}$. Results have shown that the resonating frequency has shifted towards right when composite based ring resonator was used (Fig. 15). 


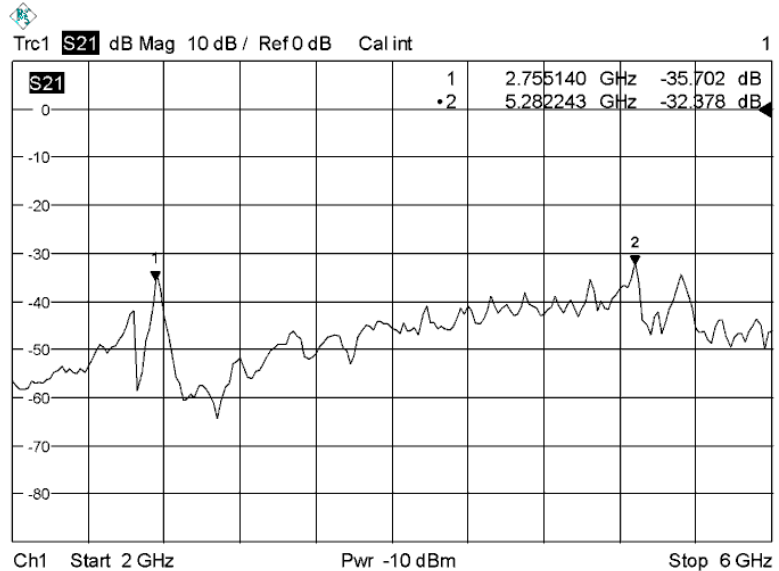

(a)
(1)

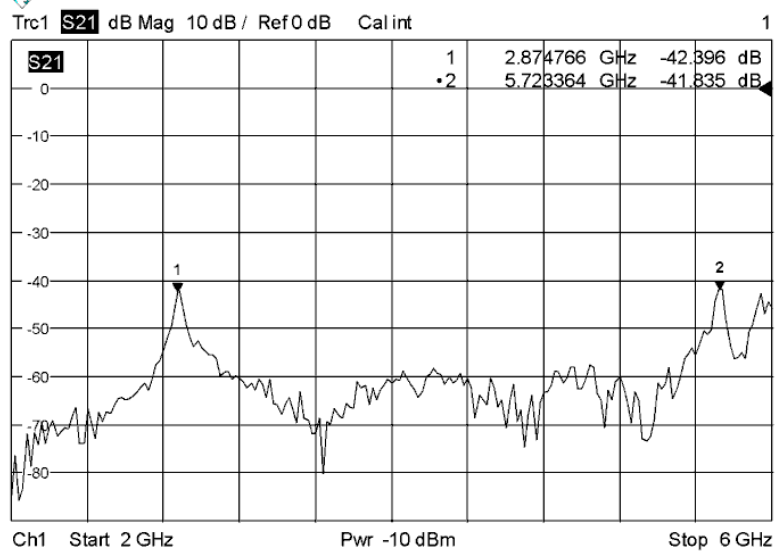

(b)

Fig. 15: Results of $S_{21}$ parameters of LDPE based ring resonator (a) and LDPE-5\%BAK (b)

\section{Calculation of $\varepsilon_{r}$}

The $\varepsilon_{r}$ for both substrates has been calculated by using the equations from the previous literature of ring resonator [39]. The relative permittivity can be extracted from the effective relative permittivity and the dimensions of the feed line [39] by using equations as follows:

$\varepsilon_{r}=\frac{2 * \varepsilon_{e f f}+M-1}{M+1}$

$\varepsilon_{e f f}=\left(\frac{n * C}{2 \Pi * R * f_{0}}\right)^{2}$

$M=\left(1+\frac{12 * h}{w_{e f f}}\right)^{-0.5}$

$w_{e f f}=w+\frac{1.25 * t}{\Pi}\left(1+\ln \left(\frac{2 h}{t}\right)\right)$

Where,

$\varepsilon_{r}=$ relative permittivity/dielectric constant

$\varepsilon_{e f f}=$ effective relative permittivity

$M=$ function of the thickness of the substrate and of the fringing effects on the micro strip edges

$C=$ the speed of light in vacuum

$R=$ mean radius of ring

$f_{0}=\mathrm{n}^{\text {th }}$ resonant frequency obtained from measurement of the insertion loss

$w_{e f f}=$ effective strip width accounting for the nonzero strip thickness

$h=$ thickness of the substrate

$w=$ strip width

$t=$ conductor thickness

Based upon equations 7-10, Table 8 shows the calculated values for resonating frequency and $\varepsilon_{r}$. 
Table 8: Calculated values for resonating frequency and $\varepsilon_{r}$

\begin{tabular}{|c|c|c|c|}
\hline Sr. No. & Substrate & $\begin{array}{c}\text { Resonating frequency } \\
(\mathrm{Ghz})\end{array}$ & Dielectric constant, $\varepsilon_{r}$ \\
\hline 1 & LDPE & 2.75 & 2.282 \\
\hline 2 & LDPE + Bakelite & 2.874 & 2.0663 \\
\hline
\end{tabular}

\section{Calculations for $\tan \delta$ :-}

$\tan \delta=\frac{\alpha_{d} \lambda_{0}}{27.3}\left(\frac{\left(\varepsilon_{r}-1\right) \sqrt{\varepsilon_{r, e f f}}}{\varepsilon_{r}\left(\varepsilon_{r, e f f}-1\right)}\right)$

The measured losses $\mathrm{Q}$ of a micro strip ring resonator can be obtained by

$Q_{0}=\frac{Q_{L}}{1-10^{\frac{L_{A}}{20}}}$

Where: $L_{A}$ is the measured insertion loss in decibels of the resonator at resonance.

The loaded loss is defined as

$Q_{L}=\frac{f_{0}}{B W_{-3 d B}}$

Where: $B W_{-3 d B}$ is the bandwidth of the resonator.

The measured attenuation constant can be given by

$\alpha_{\text {total }}=\pi\left(Q_{0} \lambda_{g}\right)\left[\frac{N_{p}}{\text { unit length }}\right]$

Where: $\lambda_{g}$ is the guided wave length.

It is known that the total attenuation constant $\left(\alpha_{\text {total }}\right)$ is the sum of the conductor attenuation factor $\left(\alpha_{c}\right)$, the dielectric attenuation factor $\left(\alpha_{d}\right)$ and radiation attenuation factor $\left(\alpha_{r}\right)$

$\alpha_{\text {total }}=\alpha_{c}+\alpha_{d}+\alpha_{r}$

Conductor Loss attenuation constant:

Taking the thickness of the strip into account, one can get the conduction attenuation constant of a micro strip line as:

$\alpha_{c}(f)=\frac{R_{S 1}}{Z_{0} h\left\{\frac{w_{\text {eff }}}{h}+\frac{2}{\pi} \ln \left[2 \pi e\left(\frac{W_{\text {eff }}}{2 h}+0.94\right)\right]\right\}^{2}} \times\left[\frac{w_{\text {eff }}}{h}+\frac{\frac{w_{\text {eff }}}{\pi h}}{\frac{W_{\text {eff }}}{2 h}+0.94}\right] \cdot\left\{1+\frac{h}{w_{\text {eff }}}+\frac{h}{\pi w_{\text {eff }}} \times\left[\ln \left(\frac{2 h}{t}+1\right)-\right.\right.$
$\left.\left.\frac{1-\frac{t}{h}}{1+\frac{t}{2 h}}\right]\right\}\left[\frac{N_{p}}{\text { unit length }}\right]$

$R_{S 1}=R_{S}\left\{1+\frac{2}{\pi} \tan ^{-1}\left(1.4\left(\frac{\Delta}{\delta_{s}}\right)^{2}\right)\right\}$,

$R_{s}=\sqrt{\left(\frac{\pi \mu f}{\sigma}\right)}$

$\delta_{s}=\sqrt{\frac{1}{\pi \mu \sigma f}}$ 
$R_{S 1}$ is the surface-roughness resistance of the micro strip.

$R_{S}$ is the surface resistance of the microstrip.

$Z_{0}$ is the characteristics impedance of the microstrip.

$\delta_{s}$ is the skin depth of $\mathrm{Cu}$.

$\mu=4 \pi \times 10^{-7} \mathrm{H} / \mathrm{m}, \sigma$ is bulk conductivity of the metal, $f$ is frequency.

$\Delta$ is the mean surface roughness of the $\mathrm{Cu}$ trace.

Radiation loss attenuation constant:

One may get the radiation quality factor of a micro strip circular resonator:

$Q_{r}=\frac{\varepsilon_{r, e f f} Z_{0}}{120 \pi^{3}\left(\frac{h}{\lambda_{0}}\right)^{2}\left(1-\frac{4}{3} \varepsilon_{r}+\frac{8}{15} \varepsilon_{r}^{2}\right)}$

Where $\epsilon$ and $\mu$ are the permittivity and permeability of the dielectric substrate respectively, $Z_{0}$ is the characteristic impedance. Where, $h$ is the thickness of substrate, $\lambda_{0}$ is the wavelength of the resonance signal in the free space. The radiation attenuation constant of the ring can be given as:

$\alpha_{r}=\frac{\pi}{Q_{r} \lambda_{g}}\left[\frac{N_{p}}{\text { unit length }}\right]$

$\alpha_{d}$ can be calculated by putting the values of $\alpha_{\text {total }}, \alpha_{c}$ and $\alpha_{r}$ in equation 15.

Based upon equations 11-18, Table 9 shows the calculated values for $\tan \delta$.

Table 9: Calculated values for $\tan \delta$

\begin{tabular}{|c|c|}
\hline Substrate & $\tan \delta$ \\
\hline LDPE & 0.0045 \\
\hline LDPE + 5\%BAK & 0.0051 \\
\hline
\end{tabular}

\section{Designing of patch antenna}

The patch of antenna has to be designed based on the specifications such as the resonating frequency, patch length, patch width and effective dielectric constant for each material. In this study the patch antenna has been designed for a resonating frequency of $2.45 \mathrm{GHz}$ with 0.75 substrate thickness.

The equation given below gives the width of the patch of antenna [31] :-

$$
W=\frac{c}{2 f_{r}} \sqrt{\left(\frac{2}{\epsilon_{r}+1}\right)}
$$

Here,

$\mathrm{W}=$ width of the patch,

$f_{r}=$ resonant frequency,

$\epsilon_{r}=$ dielectric constant

The effective dielectric constant, $\in_{e f f}$ is given by the following equation [31] :-

$$
\epsilon_{e f f}=\left[\frac{\epsilon_{r}+1}{2}\right]+\left[\left(\frac{\epsilon_{r}-1}{2}\right)\left(1+12 \frac{h}{W}\right)^{-0.5}\right]
$$

Here, 
$\mathrm{h}=$ thickness of the substrate

The value of $\Delta L$, the fring factor, need to be calculated to find the length of the patch [31]:-

$$
\Delta L=0.42 h\left[\frac{\left(\epsilon_{e f f}+0.3\right)\left(\frac{w}{h}+0.264\right)}{\left(\epsilon_{e f f}-0.258\right)\left(\frac{w}{h}+0.8\right)}\right]
$$

The length of patch is calculated as [31]:-

$$
L=\frac{1}{2 f_{c} \sqrt{\left(\epsilon_{e f f} \epsilon_{0} \mu_{0}\right)}}-2 \Delta L
$$

The dimensions of the patch are obtained by following equations[7] :-

$$
\begin{aligned}
& W_{s}=W+6 h \\
& L_{s}=L+6 h
\end{aligned}
$$

Here, $W_{S}$ and $L_{s}$ are width and length of the substrate respectively and $\mathrm{h}$ is the thickness of the substrate.

The calculated dimensions for length and width of patch (using equations 19-24) are shown in Table 10.

Table 10: Dimensions of patch for both antennas at resonating frequency $2.45 \mathrm{GHz}$

\begin{tabular}{|c|c|c|}
\hline Substrate & $\begin{array}{c}\text { Length of patch } \\
(\mathrm{mm})\end{array}$ & $\begin{array}{c}\text { Width of patch } \\
(\mathrm{mm})\end{array}$ \\
\hline LDPE & 40.21776 & 47.79052 \\
\hline LDPE + 5\%BAK & 42.23297 & 49.44619 \\
\hline
\end{tabular}

Further simulation for patch antenna was performed by using high frequency structure simulator (HFSS) 15.0.3 to simulate the patch antennas for resonating frequency of $2.45 \mathrm{GHz}$ (Fig. 16). Table 11 shows MPA characteristics based upon simulation. 


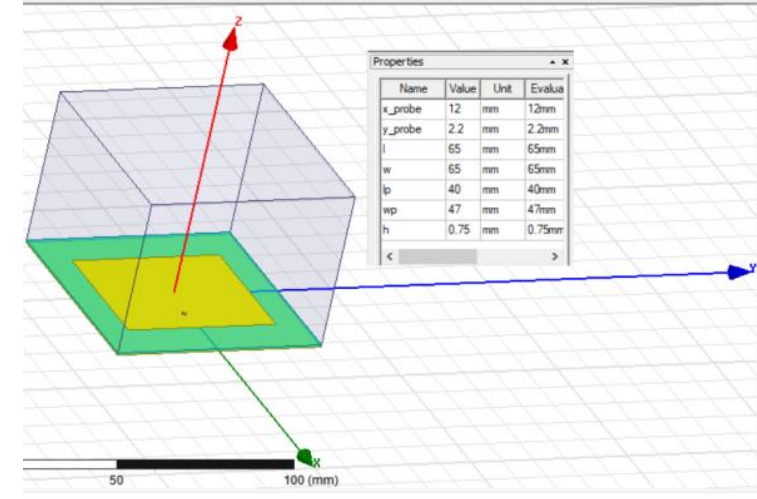

(a)

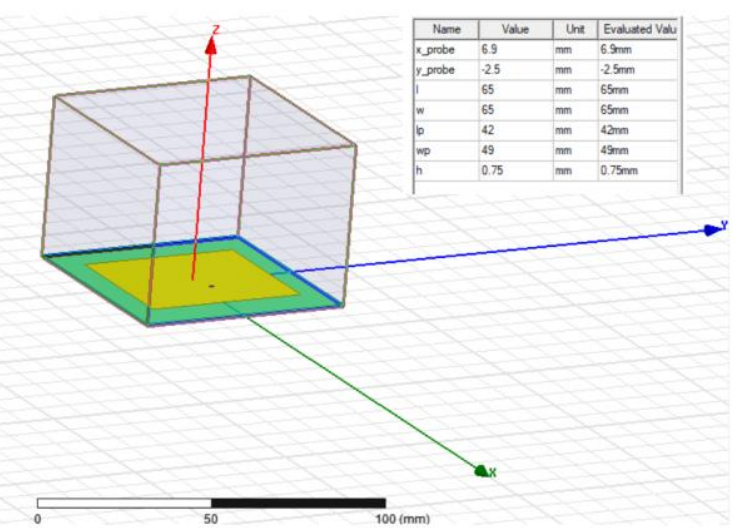

(b)

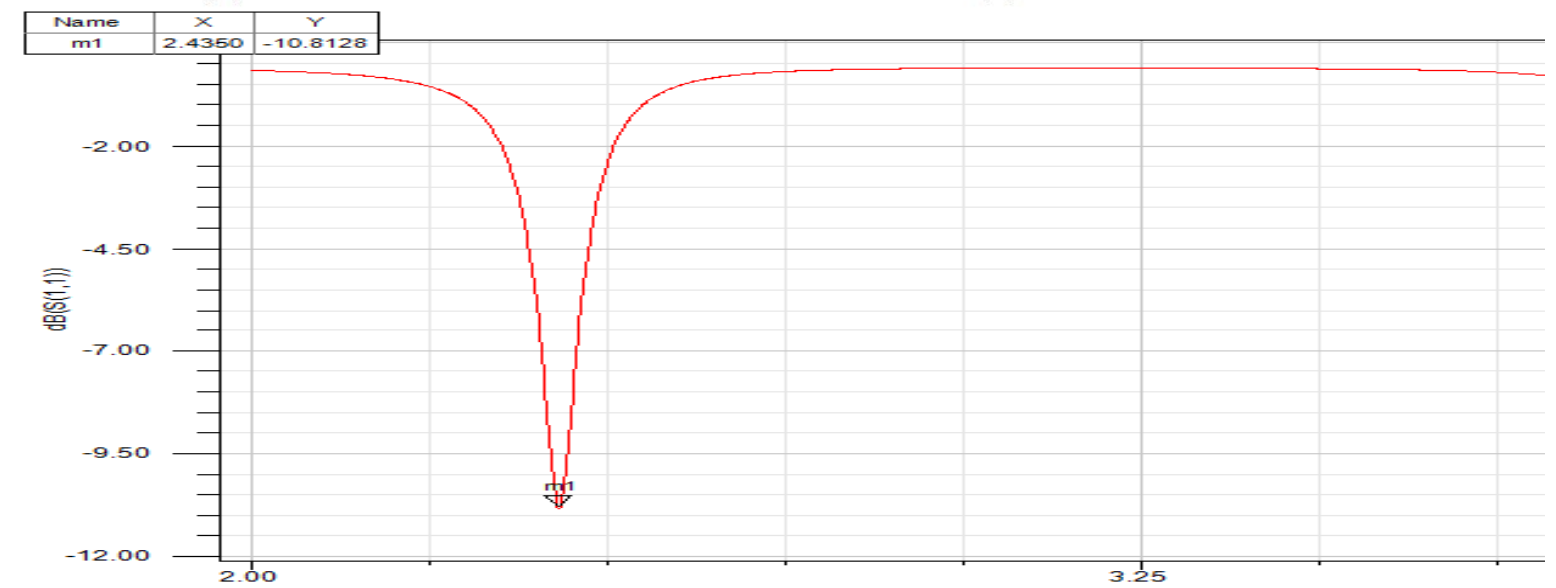

(c)

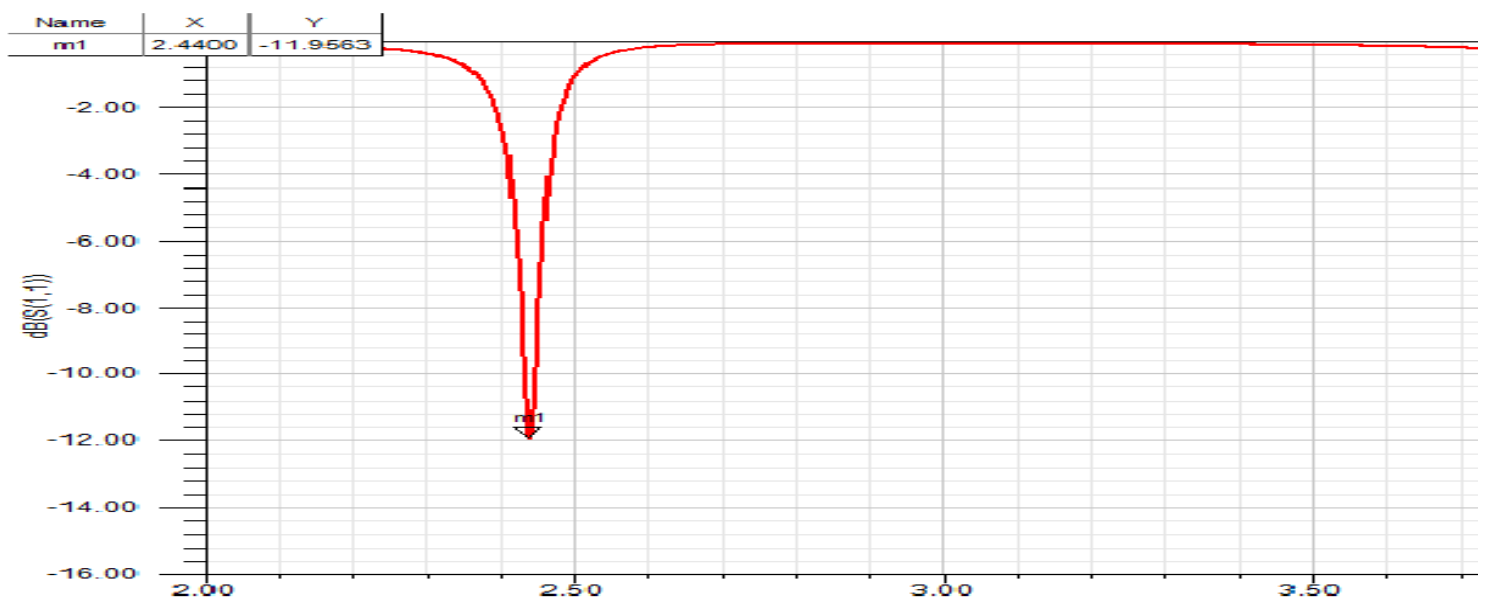

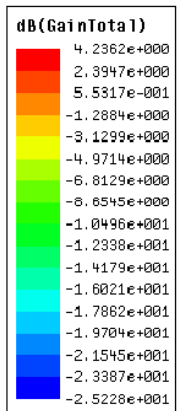

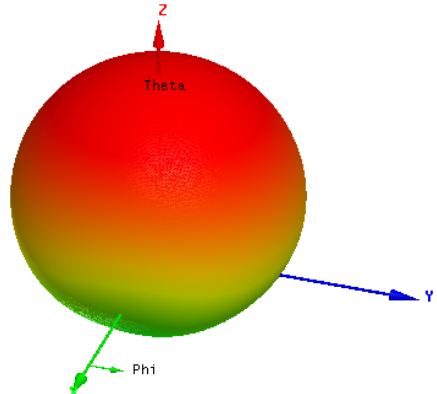

(f) 
Fig. 16: Simulation results based design parameters of antenna LDPE (a), LDPE-5\% BAK (b), Return loss parameters of LDPE (c), Return loss parameters of LDPE-5\%BAK (d), gain of LDPE (e) and gain of LDPE-5\%BAK (f)

Table 11: MPA characteristics (Simulated Results)

\begin{tabular}{|c|c|c|}
\hline Parameters $($ at $2.45 \mathrm{GHz})$ & LDPE based MPA & LDPE-5\%BAK based MPA \\
\hline Return loss $(\mathrm{dB})$ & -10.8128 & -11.9563 \\
\hline Gain $(\mathrm{dB})$ & 4.2362 & 4.2374 \\
\hline
\end{tabular}

\section{Conclusions:}

Following are the conclusions from this study:

1. In this study LDPE and LDPE-5\%BAK substrate based MPA has been successfully prepared for resonating frequency of $2.45 \mathrm{GHz}$. Hence the proposed way of preparing antenna/ sensors may be considered as a novel route for waste management of thermoplastic and thermosetting based polymers with value added product as final output. This may help for better plastic solid waste management.

2. As regards to RF characteristics of antenna is concerned better results were observed for LDPE-5\%BAK in terms of return loss, gain. However there was marginal increase in size of patch in MPA. The observed RF characteristics are in line with mechanical, morphological and surface properties of the printed substrate selected in present investigations.

3. As regards to material processing for substrate printing is concerned, the MFI of LDPE was observed more than LDPE-5\%BAK. But both substrate material well falls in suitable range for 3D printing on FDM setup.

4. In this study the mechanical properties of LDPE-5\%BAK substrate has been explored for PS maximization viewpoint and best settings were observed at $190^{\circ} \mathrm{C}$ screw temperature, 110 rpm and $11 \mathrm{~kg}$ load (based upon DoE).

Further studies may be performed for multifactor optimization view point by considering different mechanical properties for customization required as per sensor application. Also the analysis for thermal stability of LDPE-5\%BAK in comparison to LDPE may be performed for high temperature sensor applications as the reinforcement of thermosetting material will certainly improve the heat capacity of the substrate material used in MPA.

\section{Acknowledgement:}

The research has been partially funded under NTU-PU collaborated project titled "Wearable 3D printed patch antenna". Most part has been done at the Manufacturing research lab, GNDEC, Ludhiana and National Institute of Technical Teachers Training and Research, Chandigarh (under PU Chandigarh).

\section{References:}

[1] G. Laria, R. Gaggino, L. E. Peisino, and A. Cappelletti, "Mechanical and processing properties of recycled PET and LDPE-HDPE composite materials for building components," 2020, doi: $10.1177 / 0892705720939141$.

[2] S. Kumar, R. Singh, and A. Batish, "On investigation of rheological , mechanical and morphological characteristics of waste polymer-based feedstock filament for 3D printing applications," 2019, doi: 10.1177/0892705719856063.

[3] R. Singh, I. Singh, and R. Kumar, "Waste thermosetting polymer and ceramic as reinforcement in thermoplastic matrix for sustainability: Thermomechanical investigations," 
pp. 1-13, 2019, doi: 10.1177/0892705719847237.

[4] H. Salmah, A. Romisuhani, and H. Akmal, "Properties of low-density polyethylene/palm kernel shell composites: Effect of polyethylene co-acrylic acid," 2013, doi: $10.1177 / 0892705711417028$.

[5] A. Khattab, C. Liu, W. Chirdon, and C. Hebert, "Composite Materials," 2013, doi: $10.1177 / 0892705711432361$.

[6] D. Sarmah, J. R. Deka, and S. Bhattacharyya, "Study of LDPE / TiO 2 and PS / TiO 2 Composites as Potential Substrates for Microstrip Patch Antennas," vol. 39, no. 10, pp. 23592365, 2010, doi: 10.1007/s11664-010-1335-9.

[7] V. bankey and N. A. Kumar, "Design and performance issues of Microstrip antennas," Int. J. Sci. Eng. Res., vol. 6, no. 3, pp. 1572-1580, 2015, doi: 10.14299/ijser.2015.03.008.

[8] N. Sakib, S. N. Ibrahim, M. Ibn Ibrahimy, M. S. Islam, and M. M. H. Mahfuz, "Design of Microstrip Patch Antenna on Rubber Substrate with DGS for WBAN Applications," 2020 IEEE Reg. 10 Symp. TENSYMP 2020, no. August, pp. 1050-1053, 2020, doi: 10.1109/TENSYMP50017.2020.9230707.

[9] I. Khan, G. D., R. Gunjal, and R. Rashmitha, "Review of MSP Antenna Design for Various Substrates," SSRN Electron. J., pp. 1-4, 2018, doi: 10.2139/ssrn.3230632.

[10] T. J. Salai Thillai and T. R. Ganesh Babu, "Rectangular Microstrip Patch Antenna at ISM Band," Proc. 2nd Int. Conf. Comput. Methodol. Commun. ICCMC 2018, no. Iccmc, pp. 91-95, 2018, doi: 10.1109/ICCMC.2018.8487877.

[11] G. Kaur and S. Goyal, "To Study the Effect of Substrate Material for Microstrip Patch Antenna," Int. J. Eng. Trends Technol., vol. 36, no. 9, pp. 490-493, 2016, doi: 10.14445/22315381/ijett-v36p289.

[12] A. Rida, L. Yang, R. Vyas, S. Bhattacharya, and M. M. Tentzeris, "Design and Integration of Inkjet-printed Paper-Based UHF Components for RFID and Ubiquitous Sensing Applications," no. October, pp. 724-727, 2007.

[13] Constantine A. Balanis, ANTENNA THEORY ANALYSIS AND DESIGN, 4th editio. John Wiley \& Sons, Inc., Hoboken, New Jersey, 2016.

[14] I. Singh and V. S. Tripathi, "Micro strip Patch Antenna and its Applications : a Survey," vol. 2, no. 5, pp. 1595-1599, 2011.

[15] L. Rodrigues, T. Varum, and J. N. Matos, "The Application of Reconfigurable Filtennas in Mobile Satellite Terminals,” vol. XX, pp. 1-9, 2020, doi: 10.1109/ACCESS.2020.2989529.

[16] P. G. Student, "Micro strip Patch Antenna for Satellite Communication," vol. 3, no. 24, pp. 346-351, 2017.

[17] L. Vishalkumar, P. K. Sandip, and P. S. S. Kashyap, "Design of Planar Microstrip Patch Antenna for GPS Application," no. April 2015, 2016.

[18] C. Andriesei, "Microstrip patch antennas for gps applications," no. March, 2020.

[19] H. C. N. R. L. S. K. Sharma, "Design of an embedded-feed type microstrip patch antenna for UHF radio frequency identification tag on metallic objects," vol. 4, no. August 2009, pp. 1232-1239, 2010, doi: 10.1049/iet-map.2009.0407.

[20] C. Series, "Wideband slotted microstrip patch antenna for UHF-RFID reader," 2021, doi: $10.1088 / 1742-6596 / 1755 / 1 / 012028$.

[21] N. Chater, T. Mazri, and M. Benbrahim, "Design and simulation of microstrip patch array 
antenna for electronic scanning Radar application,” pp. 1-5, 2017.

[22] Y. E. V. Kumar, B. Srinivas, V. P. Kumar, T. Kamalesh, and A. Mounica, "Novel Design of Thz Microstrip Patch Antenna for Radar Applications," no. 6, pp. 1111-1113, 2019.

[23] S. Malisuwan, N. Tiamnara, and N. Suriyakrai, "Design of Antennas for a Rectenna System of Wireless Power Transfer in the LTE / WLAN Frequency Band," vol. 5, no. 1, pp. 42-46, 2017, doi: 10.18178/jocet.2017.5.1.341.

[24] F. Ahmed and R. Soomro, "Design of Wearable Microstrip Yagi Array Antenna aimed for Telemedicine Applications," no. October, 2017.

[25] W. Grabssi, S. Izza, and A. Azrar, "Design and Analysis of a Microstrip Patch Antenna for Medical Applications," 2017.

[26] Mohd Ifwat Mohd Ghazali, Eleazar Gutierrez, Joshua C. Myers, Amanpreet Kaur, Brian Wright, Premjeet Chahal., "Affordable 3D Printed Microwave Antennas," pp. 240-246, 2015.

[27] Liang, Min Member, Student Shemelya, Corey Macdonald, Eric Wicker, Ryan Xin, Hao Member, Sr., "3D printed microwave patch antenna via fused deposition method and ultrasonic wire mesh embedding technique," vol. 1225, no. c, pp. 10-13, 2015, doi: 10.1109/LAWP.2015.2405054.

[28] S. Kumar, R. Singh, T. P. Singh, and A. Batish, "Comparison of mechanical and morphological properties of 3-D printed functional prototypes: Multi and hybrid blended thermoplastic matrix," pp. 1-16, 2020, doi: 10.1177/0892705720925136.

[29] R. Singh, R. Kumar, and I. Singh, "Investigations on 3D printed thermosetting and ceramicreinforced recycled thermoplastic- based functional prototypes," 2019, doi: $10.1177 / 0892705719864623$.

[30] T. Singh, S. Kumar, and S. Sehgal, "3D printing of engineering materials: A state of the art review," Mater. Today Proc., vol. 28, no. xxxx, pp. 1927-1931, 2020, doi: 10.1016/j.matpr.2020.05.334.

[31] N. H. Manab, E. Baharudin, F. C. Seman, and A. Ismail, "2.45 GHz Patch Antenna Based on Thermoplastic Polymer Substrates," RFM 2018 - 2018 IEEE Int. RF Microw. Conf. Proc., pp. 93-96, 2018, doi: 10.1109/RFM.2018.8846493.

[32] N. Abdul Malek, A. Mohd Ramly, A. Sidek, and S. Yasmin Mohamad, "Characterization of acrylonitrile butadiene styrene for 3D printed patch antenna," Indones. J. Electr. Eng. Comput. Sci., vol. 6, no. 1, pp. 116-123, 2017, doi: 10.11591/ijeecs.v6.i1.pp116-123.

[33] F. Slimani, A. Hedir, M. Moudoud, and F. Bellabas, "Dielectric and Mechanical Behavior of Low Density Polyethylene ( LDPE) Under Thermal Constraint," no. June, pp. 2-5, 2019.

[34] R. Singh, I. Singh, and R. Kumar, "Mechanical and morphological investigations of 3D printed recycled ABS reinforced with bakelite-SiC-A12O3," Proc. Inst. Mech. Eng. Part C J. Mech. Eng. Sci., vol. 233, no. 17, pp. 5933-5944, 2019, doi: 10.1177/0954406219860163.

[35] S. Oval1, "Investigating the effect of the aging process on LDPE composites with UV protective additives," pp. 1-19, 2020, doi: 10.1177/0892705720941908.

[36] M. I. Ahmed, M. F. Ahmed, and A. A. Shaalan, "Investigation and Comparison of 2. $4 \mathrm{GHz}$ Wearable Antennas on Three Textile Substrates and Its Performance Characteristics," pp. 110 120, 2017, doi: 10.4236/ojapr.2017.53009.

[37] A. K. V. Deshmukh, "Dielectric Properties Measurement Using Ring Resonator," Int. J. Sci. Res., vol. 4, no. 4, pp. 2361-2364, 2015, [Online]. Available: https://www.ijsr.net/archive/v4i4/SUB153688.pdf. 
[38] F. O. F. Engineering, "Design of Singly Split Single Ring Resonator for Measurement of Dielectric Constant of Materials using Resonant Method," no. June, 2013.

[39] L. Yang, A. Rida, R. Vyas, and M. M. Tentzeris, "RFID tag and RF structures on a paper substrate using inkjet-printing technology," IEEE Trans. Microw. Theory Tech., vol. 55, no. 12, pp. 2894-2901, 2007, doi: 10.1109/TMTT.2007.909886. 